\title{
Fault Diagnosis for Steam-flow Exciting Vibration of Ultra Supercritical 1000 MW Steam Turbine
}

\author{
Chen $\mathrm{Li}^{*}$ and $\mathrm{Hu}$ Niansu \\ School of Power and Mechanical Engineering, Wuhan University/Wuhan, Hubei, 430072, P. R. China
}

\begin{abstract}
With the increase in thermal power capacity, ultra supercritical units have become the mainstream of power industry. At the same time, with the improvement of the steam parameters and the lengthening of shafting, the production of steam flow excited vibration is frequent in the ultra supercritical units, which may seriously affect the reliability of the unit. This paper has taken steam flow excited vibration of a 1000MW turbine as an example in accordance with the experimental and theoretical causes of steam flow excited vibration to solve the problem of steam flow excited vibration by the proposed treatment plan. This can greatly improve the reliability of operation and the units with high load capacity.
\end{abstract}

Keywords: 1000MW steam turbine, Admission mode, Rotor eccentricity, Seal, Steam-flow exciting vibration.

\section{INTRODUCTION}

With the development of the electric industry, ultra supercritical thermal power unit with large capacity has become the main force of electric power industry. At present, there are more than 60 sets of supercritical 1000MW units in service, plus other 100 sets are still under construction in China. Ultra supercritical steam turbine with characteristics of high steam parameters, long shafting and more bearings, increases the possibility of the steam flow excited vibration. These kinds of related problems arise in many $1000 \mathrm{MW}$ units including Nanjing power plant, Waigaoqiao Power Plant, Suizhong power plant, Xinmi power plant, Hezhou power plant etc., that seriously affect the safety of steam turbine. Therefore, how to solve the following induced vibration problem of ultra supercritical 1000MW unit has become an important topic for ensuring a reliable operation of the unit.

\section{UNIT OVERVIEW}

The model N1000-25/600/60 of a steam turbine which is used for production in Dongfang Steam Turbine Factory possesses the following parameters as supercritical: an intermediate reheat, single shaft, four cylinder four exhausts, double back pressure, the eight stage regenerative, and condensing steam turbine. Its rated primary steam pressure/ temperature is $25 \mathrm{MPa} / 600 \mathrm{DEG} \mathrm{C}$ and rated reheated steam inlet pressure/temperature is 4. $225 \mathrm{MPa} / 600 \mathrm{C}$. The critical speed of the rotor section is shown in Table $\mathbf{1}$.

In the design of shaft cold installation curve, considering the amount of the rotor bearing elevation changes in the thermal

*Address correspondence to this author at the School of Power and Mechanical Engineering, Wuhan University/Wuhan, Hubei, 430072, P. R. China; Tel: 027-68773317; Fax: 027-68773317

E-mail: chenli12530@sina.com state, the compensation of elevation variation determined by the calculation and the test value for ensuring the center of rotation shaft in the working condition becomes a smooth curve. Installation of lift curve is shown in Fig. (1).

Table 1. The critical speed of rotor sections.

\begin{tabular}{|c|c|c|}
\hline $\begin{array}{c}\text { Shaft } \\
\text { Section }\end{array}$ & $\begin{array}{c}\text { The First Critical Speed } \\
\text { (R/min) }\end{array}$ & $\begin{array}{c}\text { The Second Critical Speed } \\
\text { (R/min) }\end{array}$ \\
\hline \hline HP rotor & 1960 & $>4500$ \\
\hline MP rotor & 2040 & $>4500$ \\
\hline L P rotor A & 1680 & 3680 \\
\hline L P rotor B & 1720 & 3830 \\
\hline Gen rotor & 850 & 2390 \\
\hline
\end{tabular}

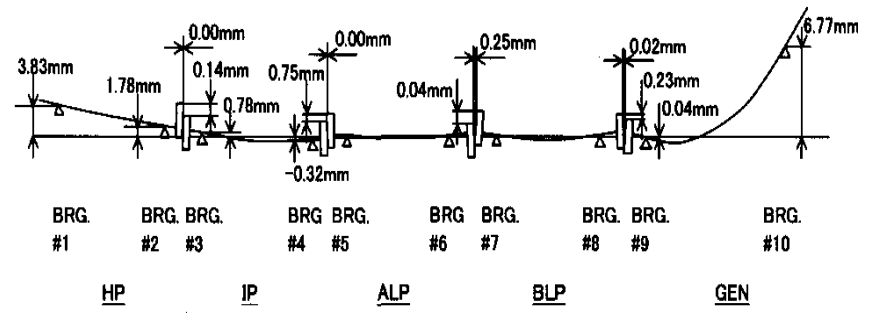

Fig. (1). Rotor mounted lift curve.

During the period of trial operation stage, the turbine starts to vibrate when the load reaches about $90 \%$ of the rated load and the parameters of unit are normal before the vibration. But the turbine reaching the point of load (926MW) induces a sharp vibration while shaft vibration $1 Y$ reaches $260 \mu \mathrm{m}, 1 \mathrm{X}$ reaches $248 \mu \mathrm{m}$, and turbine trip completed in relatively short time(double amplitude vibration value measured on the bearing seat vertically or horizontally was not allowed to exceed $0.025 \mathrm{~mm})$. The results of the load control tests conducted several times 
show that the turbine failed to continue its load upwards when it induced sharp vibration after the load rose up to $930 \mathrm{MW}$. Fig. (2) represents the unit trip curve of $928 \mathrm{MW}$.

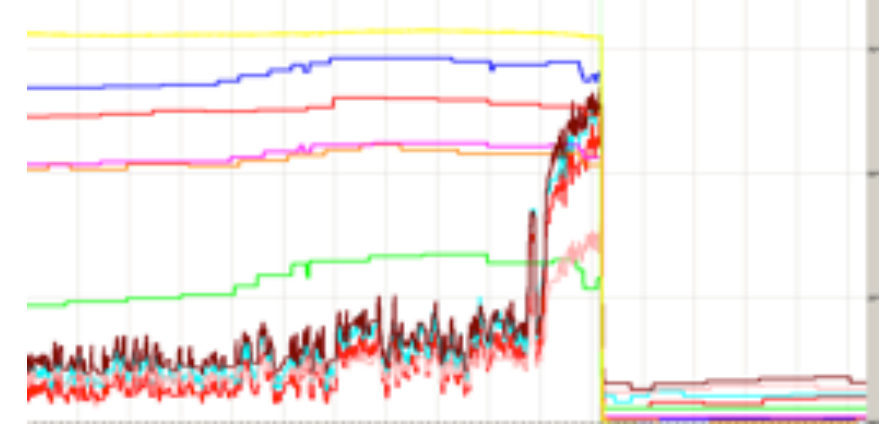

Fig. (2). The vibration curve of 928MW.

Next, the shaft vibration spectrum (Fig. 3) and Potter diagram (Fig. 4) were deduced.

By analyzing the vibration curve both before and after the trip, it can be found that the vibration began at a certain threshold load and proportional to the load which was mainly concentrated in the high pressure rotor. The vibration was in low frequency mode and the main frequency components accommodated nearly half of the working speed. In addition, because of the nonlinear characteristics of the practical steam force and the bearing oil film force, there were some other harmonic frequency components; at the same time, the possibility of imbalance induced vibration caused by thermal bending was excluded from the vibration of Potter diagram after the trip. Therefore, initially it was observed that the vibration is caused by steam flow excitation.

\section{THE REASON OF STEAM FLOW EXCITED VIBRATION}

On the basis of current research results [1-10], it has been observed that there are three main causes of steam flow excited vibration.

The first is the tip clearance excitation force. The steam turbine impeller in the eccentric position, due to the different tip clearances along the circumferential direction, does not have a uniform amount of leakage of steam in the different space position so the tangential force in each circumferential position of the impeller is different which produces a horizontal force (resultant force) on the impeller center, also known as clearance excitation force, as shown in Fig. (5). The excited force caused by tip clearance inhomogeneous is proportional to the power of steam turbine stage, and is inversely proportional to the diametric pitch and height of blade, and the speed of turbine. Therefore, the tip clearance excitation force is likely to occur in the high-pressure rotor of large turbine having high power, smaller impeller diameter and shorter blade.

The second is seal fluid force. The uneven distribution of steam pressure in shaft and diaphragm gland housing caused by the rotor dynamic eccentricity produces a resultant force perpendicular to the offset direction of the rotor. Similar to the former one, the tangential force makes the rotor motion unstable. The fluid force in the gland chamber includes

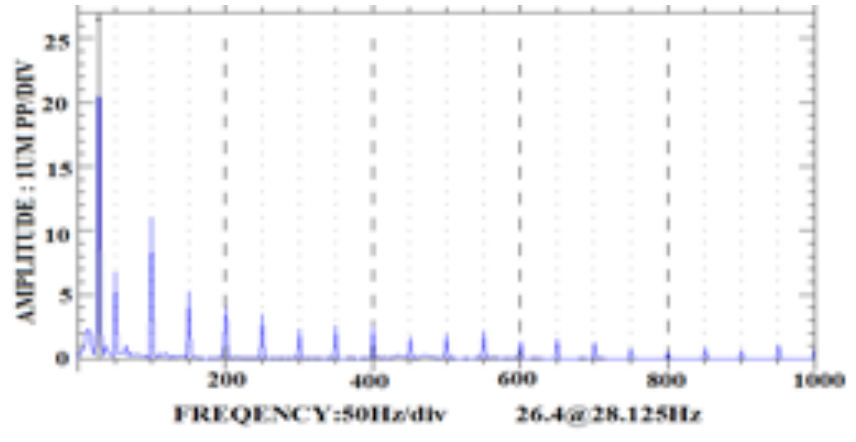

(a) \#1X direction

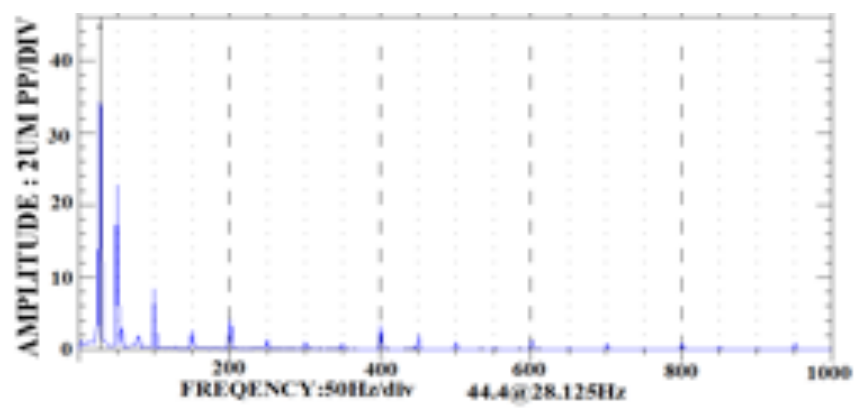

(b) \#1Y direction

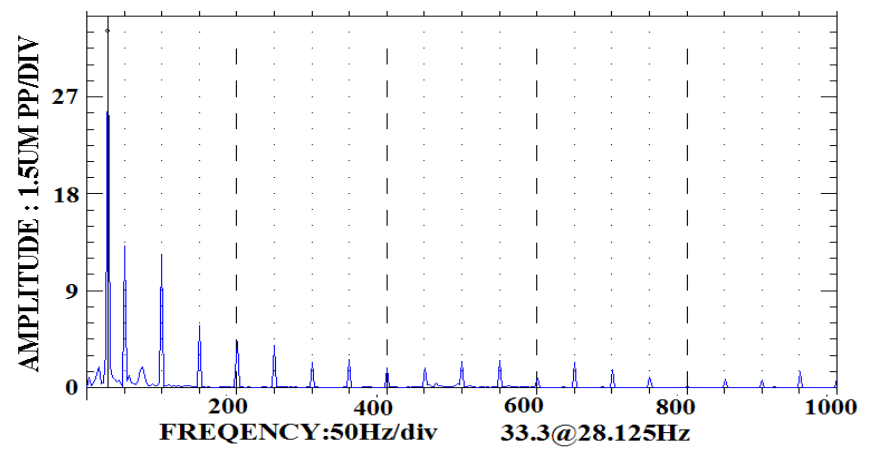

(c) \#2X direction

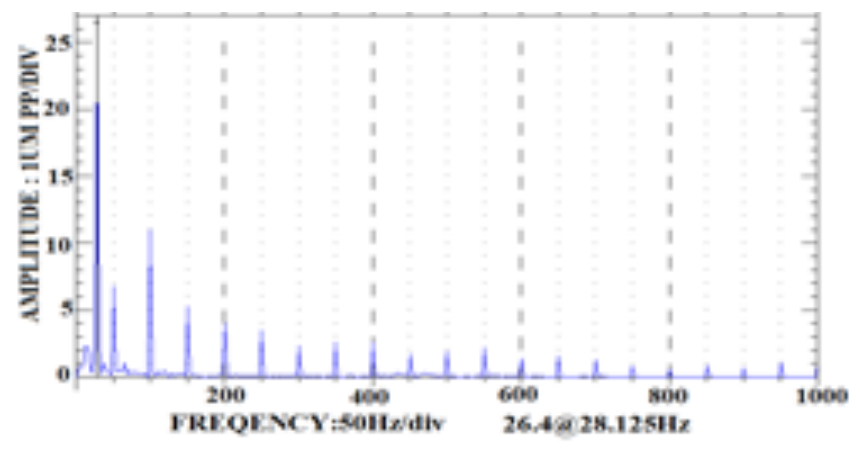

(d) \#2Y direction

Fig. (3). Shaft vibration spectrum diagram before trip.

axial flow and circumferential flow of steam force. The steam force in gland is related to the geometric size of the gland, seal steam flow rate, temperature, pressure, the seal teeth average clearance and angular velocity of the rotor . Much theoretical analysis and experimental results indicate that pre swirling speed (the circumferential velocity of steam before coming into shaft seal) has a marked effect on the seal fluid force. 


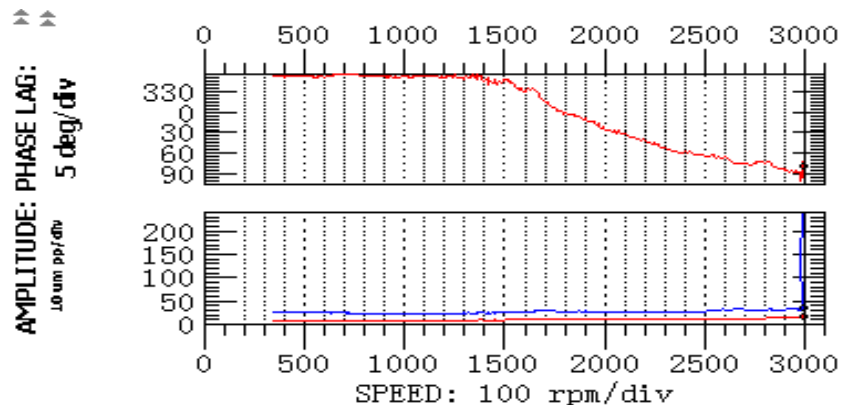

(a) \#1X direction

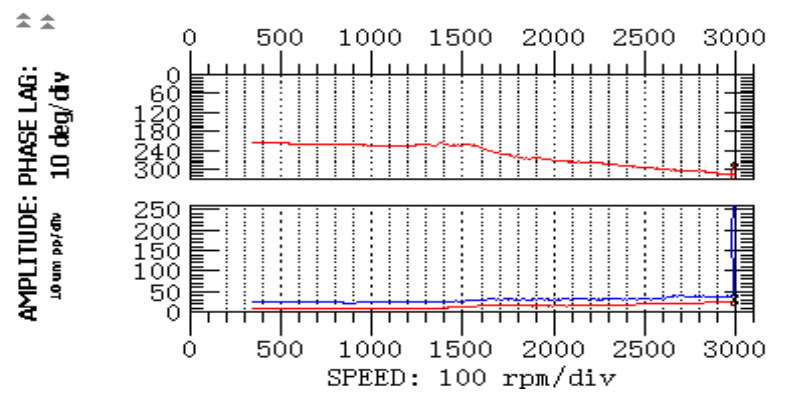

(b) \#1Y direction

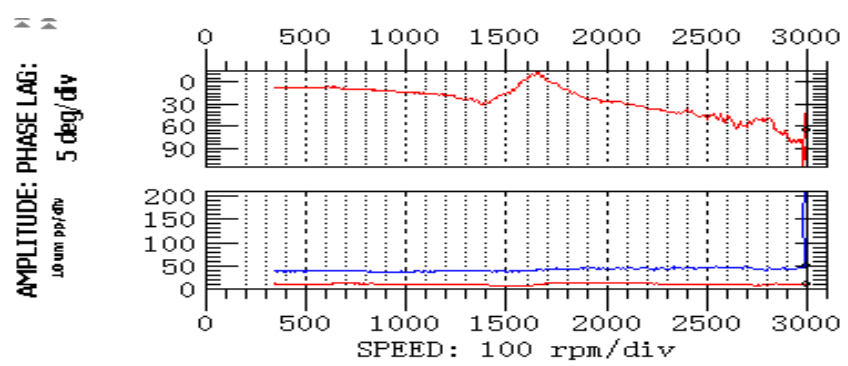

(c) \#2X direction

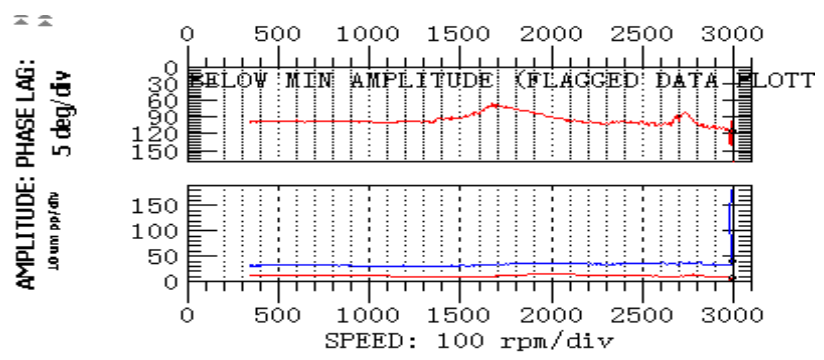

(d) \#2Y direction

Fig. (4). Vibration Potter diagram after trip.

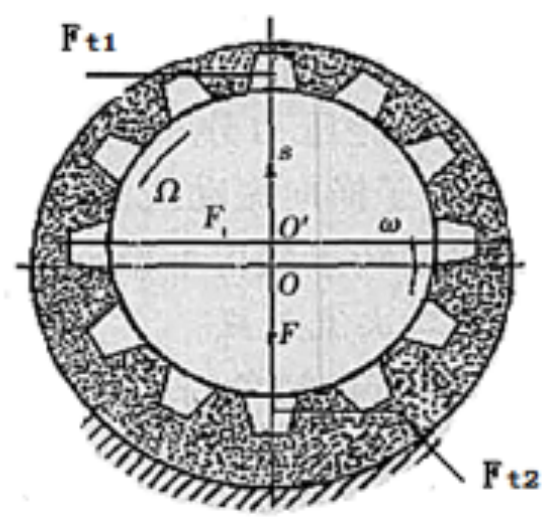

Fig. (5). Flow exciting force caused by impeller eccentricity.
The third is the static steam force. Due to different admission modes of high pressure cylinder, high pressure steam brings a steam force on the rotor. On one hand, it affects the journal in the bearing position, changing the dynamic characteristics of the bearings (bearing load changes) so as to lead to rotor instability. On the other hand, changes in the rotor radial position in the cylinder lead to the corresponding change in clearance of turbine passage which is shown in Fig. (6).

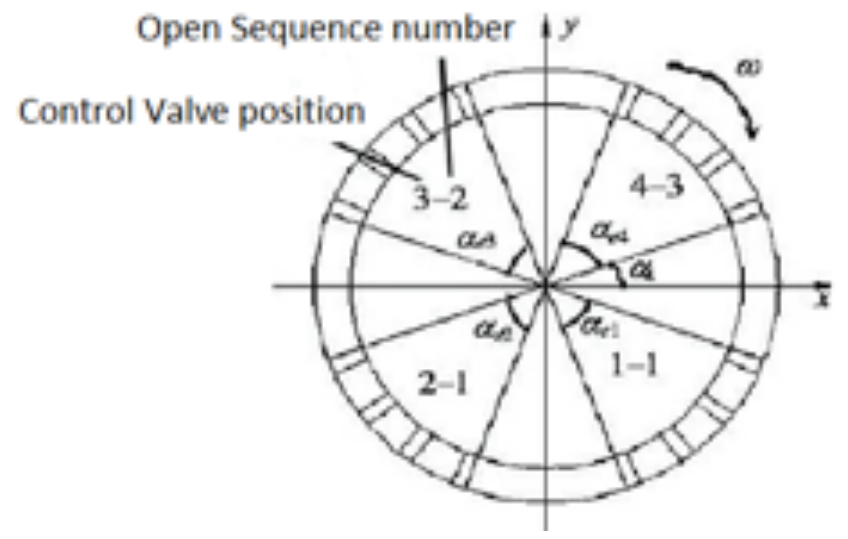

Fig. (6). Steam turbine valve opening sequence diagram.

\section{DIAGNOSIS AND TREATMENT OF STEAM FLOW EXCITED VIBRATION}

\subsection{Adjustment of the Static Steam Force}

Based on the reasons of steam flow excited vibration, the admission mode of HP cylinder is altered to avoid the static steam force as this is the easiest way to implement. This steam turbine has four main steam valves and throttles; the main steam passes through the pipes and four steam inlets on the outer casing into the adjustment stage; the original high pressure throttles opening sequence is 4231 as shown in Fig. (7). The valve control is a composite sequence; a unit is a single valve when it is under the low load and starting conditions. In order to reduce the throttle loss of valve when the load is up to $50 \%$ or so, \#1control valve is gradually turned down and reopened when the load is up to $85 \%$ as shown in Fig. (8).

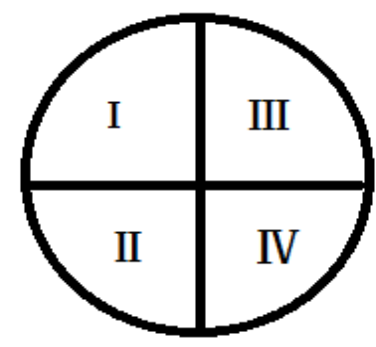

Fig. (7). Turbine valve position.

In order to find out the influence on vibration by different opening sequences of each control valve under the sequence valve control mode, a series of valve adjustment tests were conducted under different load conditions from March to April. The valve adjustment records are shown in Table 2. 


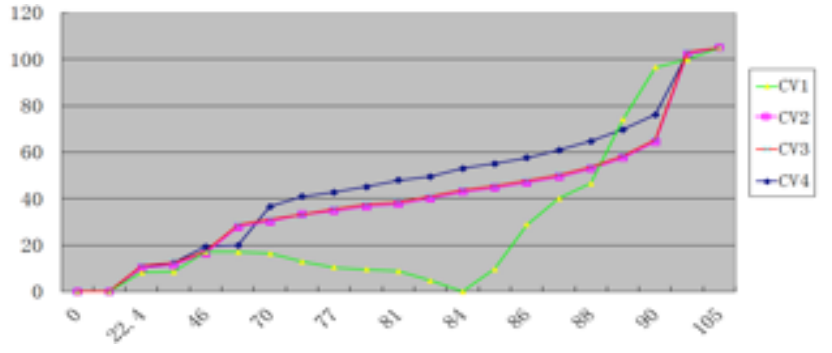

Fig. (8). The valve combination valve order.

Table 2. Control valve sequence adjustment test.

\begin{tabular}{|c|c|c|c|c|c|}
\hline 1 & Mar. 7 & $\mathrm{CV} 1 \rightarrow \mathrm{CV} 4$ & 6 & Apr. 28 & $\mathrm{CV} 3 \rightarrow \mathrm{CV} 4$ \\
\hline 2 & & $\mathrm{CV} 1 \rightarrow \mathrm{CV} 3$ & 7 & & $\mathrm{CV} 4 \rightarrow \mathrm{CV} 3$ \\
\hline 3 & & $\mathrm{CV} 1 \rightarrow \mathrm{CV} 4$ & 8 & & $\mathrm{CV} 2 \rightarrow \mathrm{CV} 4$ \\
\hline 4 & Mar. 16 & $\mathrm{CV} 1 \rightarrow \mathrm{CV} 2$ & 9 & Apr. 29 & $\mathrm{CV} 1 \rightarrow \mathrm{CV} 3$ \\
\hline 5 & Apr. 28 & $\mathrm{CV} 2 \rightarrow \mathrm{CV} 3$ & 10 & Apr. 29 & $\mathrm{CV} 3 \rightarrow \mathrm{CV} 4$ \\
\hline
\end{tabular}

The vibration data were collected in control valve switching process in the conditions as shown in Fig. (9).

It can be seen from Fig. (9a) that the control valve switch test CV1 to CV2 was conducted at $80 \%$ (800MW) load. The value of vibration did not change significantly in the switching process. Thus the load reached up to $90 \%$ (910MW), the vibration intensified, the amplitude of $1 \mathrm{X}$ direction reached $95 \mu \mathrm{m}, 1 \mathrm{Y}$ direction reached $116 \mu \mathrm{m}, 2 \mathrm{X}$ direction reached $105 \mu \mathrm{m}$ and the vibration increased. Therefore, the switching of CV1 to CV2 to improve the static steam force did not prove to be good.

Relatively, from Fig. (9b), it is evident that the control valve switch test was conducted from CV1 to CV3 at $70 \%$ load. Vibration improved in the switch process and the load reached up to $90 \%$ (910MW), the vibration increased slightly, the amplitude of $1 \mathrm{Y}$ direction was the maximum reaching $60 \mu \mathrm{m}$. Therefore, the switching from CV1 to CV3 to improve the static steam force proved to be good.

From Fig. (9c), it can be seen that the control valve switch test from CV1 switch to CV4 was conducted at $40 \%$ load. Because the load was low, the vibration altered slightly in the switch process. When the load was up to $70 \%$ (700MW), the vibration increased and the amplitude of $1 \mathrm{X}$ direction reached $65 \mu \mathrm{m}$.

However, in Fig. (9d), it is shown that at $70 \%$ load, the control valve switch test took a shift from CV2 to CV3 and the vibration altered slightly in the switch process. Then in the test from CV3 switch to CV4, the vibration increased suddenly in switch process, immediately terminating the test. Therefore, it is evident that CV3 switch to CV4 exerted much influence on vibration.

By Fig. (9e), it can be seen that at $70 \%$ load, the control valve switch test from CV2 switched to CV4, and the vibration altered little in the process. When the load was up to $80 \%(800 \mathrm{MW})$, the vibration intensified, the amplitude of $1 \mathrm{X}$ direction reached $105 \mu \mathrm{m}, 1 \mathrm{Y}$ direction reached $100 \mu$ $\mathrm{m}$ and the vibration tended to increase terminating the test immediately.
The comprehensive evaluation of the vibration of each valve in switching trials finally determines that the valve opening sequence changed from 4231 to 1243 . Then load up test was conducted passing original load limit $928 \mathrm{MW}$ rising to $961 \mathrm{MW}$. At this time, the amplitude of $1 \mathrm{X}$ direction was 86. $6 \mu \mathrm{m}, 1 \mathrm{Y}$ direction and $2 \mathrm{X}$ direction reached $102 \mu \mathrm{m}$ and $2 \mathrm{Y}$ direction was $48 \mu \mathrm{m}$. The vibration data is shown in Fig. (10).

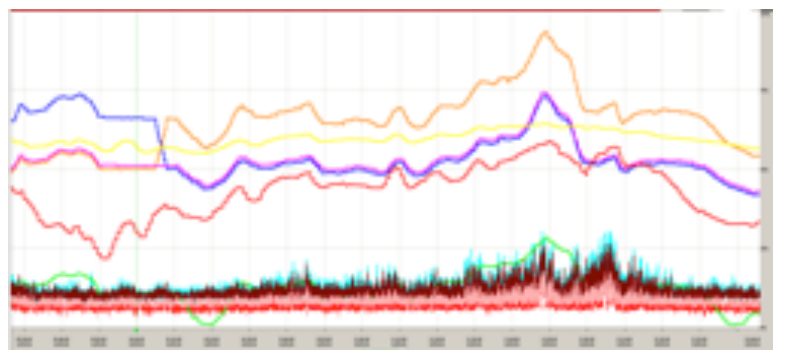

(a) $80 \%$ load CV1 $\rightarrow$ CV2

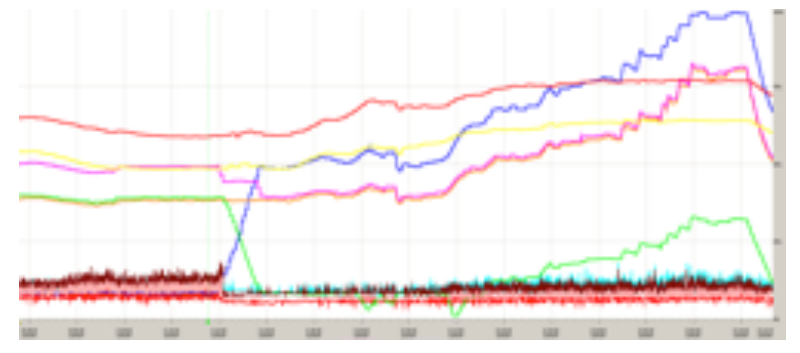

(b) $70 \%$ load, CV1 $\rightarrow$ CV3

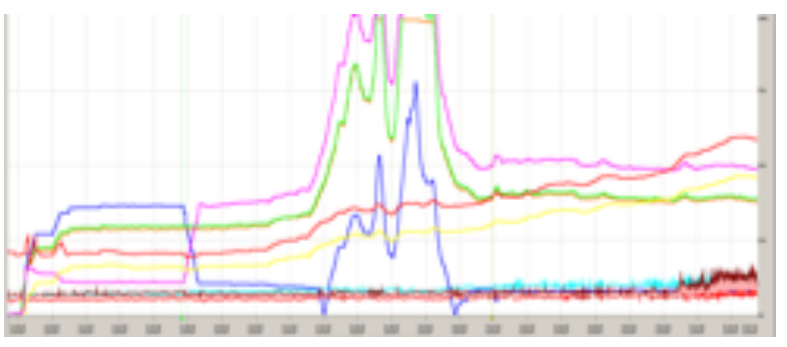

(c) $40 \%$ load, CV1 $\rightarrow$ CV4

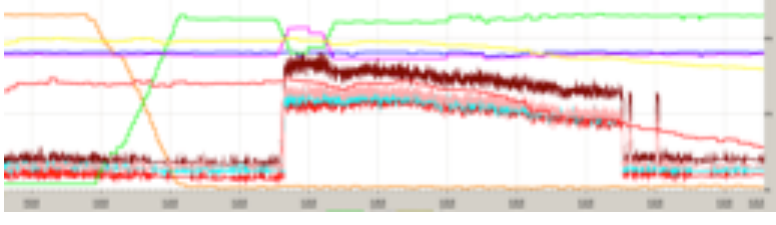

(d) $80 \%$ load, CV2 $\rightarrow$ CV3, CV3 $\rightarrow$ CV4

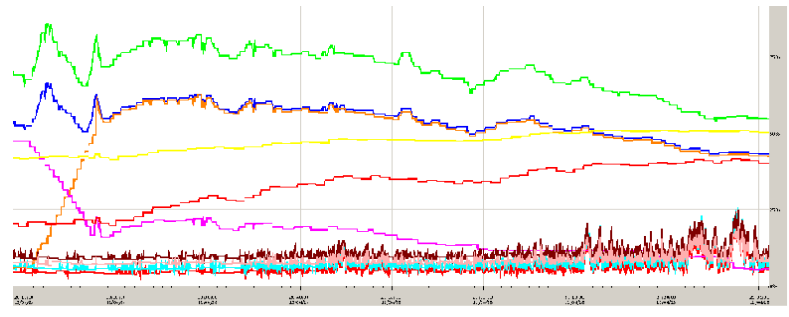

(e) $70 \%$ load, CV2 $\rightarrow$ CV4

Fig. (9). The vibration curve that controls valve sequence transformation on different load. 


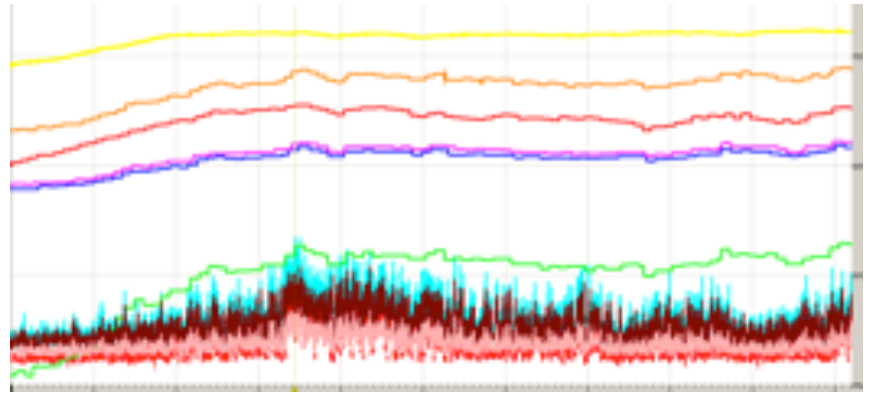

Fig. (10). The vibration curve after altering valve sequence load at 961MW.

Therefore, in this kind of valve control mode, the unit can keep the $960 \mathrm{MW}$ running but there is a certain risk in increasing it to full load; further analysis of the reason of steam flow excited vibration is needed to eliminate the influence of vibration on the unit.

\subsection{Intervention of Pre Swirling Speed at the Sealing Entrance}

Based on the analysis of the axial force of the seal, it is known that the seal steam inlet velocity and the rotor rotates make the steam in seal produce circumferential flow. Considering that the viscosity of steam is low, the rotate rotor makes steam form circumferential flow on rotor surface. And as the entrance pre swirl produces steam in seal formation circumferential, the speed is equivalent to pre swirling speed, therefore the steam pre swirl effect on the seal clearance excitation is larger. Especially, when the pre swirl turns in the same direction with the rotation of the rotor, it produces more strong seal excitation force to deteriorate the stability of the rotor. Therefore, in order to reduce the steam flow excited vibration, the steam turbine adds anti-rotating tooth at first stage blade tip seal and \#1 shaft seal of the high pressure making the direction of seal steam pre swirl in the entrance contrary to the rotor rotation in order to reduce the seal steam circumferential velocity, furthermore reducing the sealing exciting force. Inlet angle and rotor axis are at an angle of 30 degrees (Fig. 11).

\subsection{Adjustment of Shaft Eccentricity}

From the analysis of the cause of the steam excited vibration, it is known that the tip clearance excitation force and seal fluid force are related to rotor eccentricity. In the circumferential direction, the steam pressure is high when the seal clearances become small, and when the seal clearances become larger, the steam pressure turns to be lower, thus synthesizing sealing excitation force, as shown in Fig. (12). In addition, due to different pressure attenuations in each cavity seal teeth, the contribution of rotor exciting force is different but near the entrance of sealing cavity, it is maximum.

The steam flow excited vibration force such as the calculating formula of Thomas [11] is:

$$
F_{t y}=\frac{m_{0} \lambda u}{2}=\frac{d \xi_{s p}}{d \delta} e
$$

$\mathrm{m}_{0}$ - the total gas flow

$$
\begin{aligned}
& \lambda \text {-the pressure coefficient } \\
& \mu \text {-the tangential velocity at the center of the blade } \\
& \xi \text { sp - partial loss of efficiency } \\
& \delta \text {-tip clearance } \\
& \text { e-eccentricity }
\end{aligned}
$$
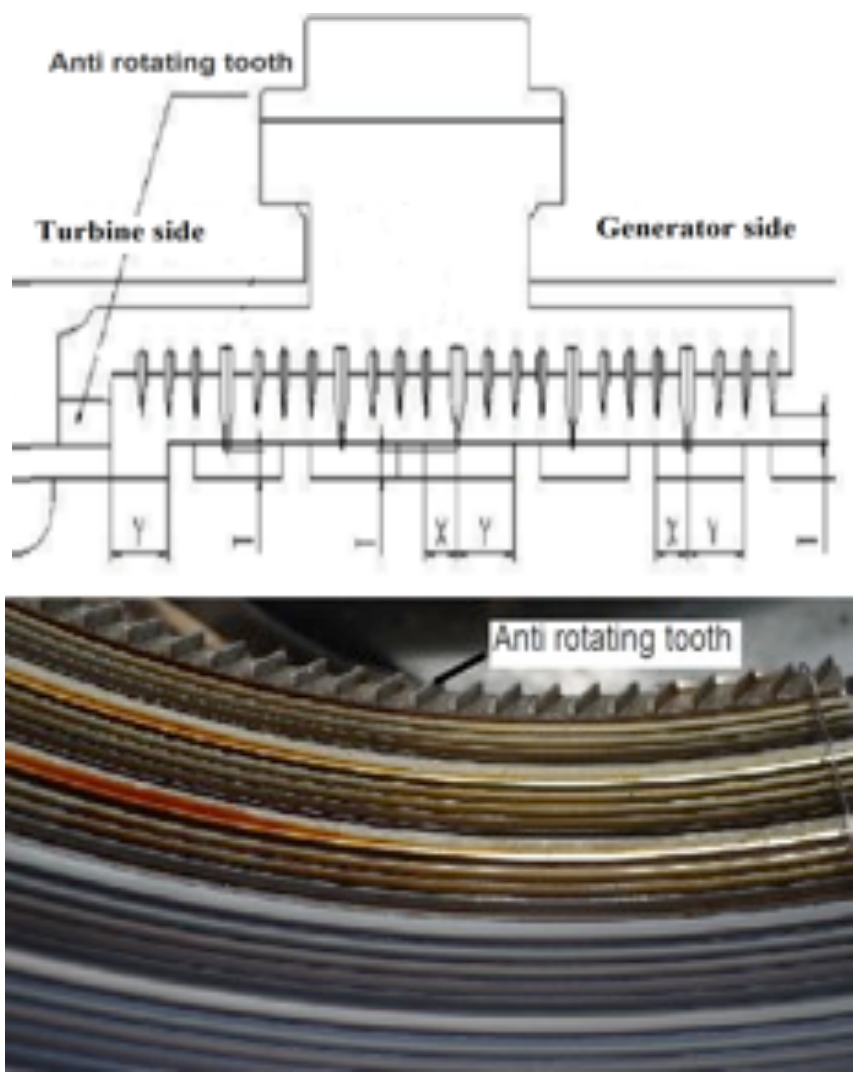

Fig. (11). Anti rotating tooth of the gland.

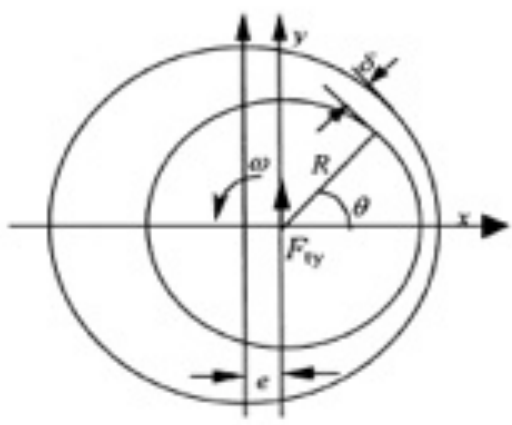

Fig. (12). The tip clearance and steam flow excited vibration force diagram.

It can be seen from the right hand side of the equation that the steam flow excited vibration force is related to blade tip clearance and eccentricity. Next, an attempt is made to analyze and solve the problem of turbine steam flow excited vibration from the eccentricity of the rotor and eccentricity leading to the tip clearance variation. Because the first stage Blade tip seal and \#1 shaft gland of high pressure rotor are the main sites that induce vibration, therefore, analysis of these two positions was mainly conducted. Its structure is 
Table 3. The rotor radius and radial clearance data.

\begin{tabular}{|c|c|c|c|c|}
\hline & Radius R(mm) & Clearance $\delta$ 1(mm) & Radius R(mm) & Clearance $\delta$ 2(mm) \\
\hline \hline First stage blade & 613 & $0.5 \pm 0.05$ & 610 & $0.4 \pm 0.05$ \\
\hline$\# 1$ shaft gland & 315.8 & $0.5 \pm 0.13$ & 311.3 & $0.4 \pm 0.13$ \\
\hline
\end{tabular}

shown in Figs. $(\mathbf{1 3}, \mathbf{1 4})$, and clearance data is shown in Table 3.

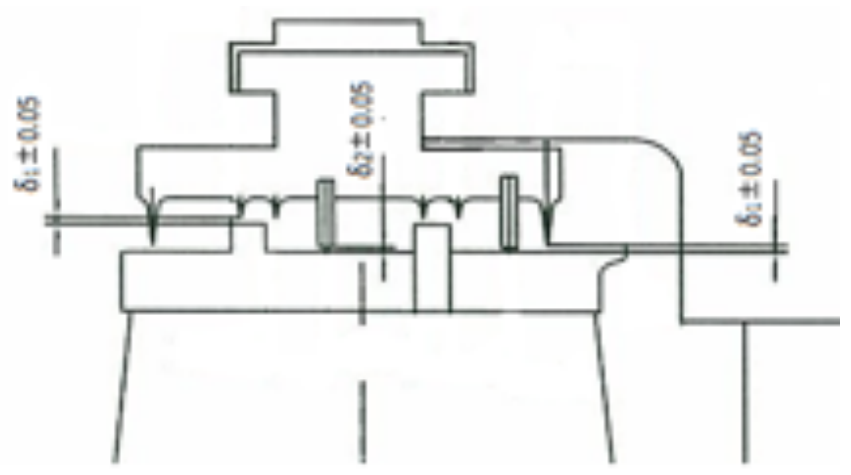

Fig. (13). The diagram of first stage high pressure rotor blade tip clearance.

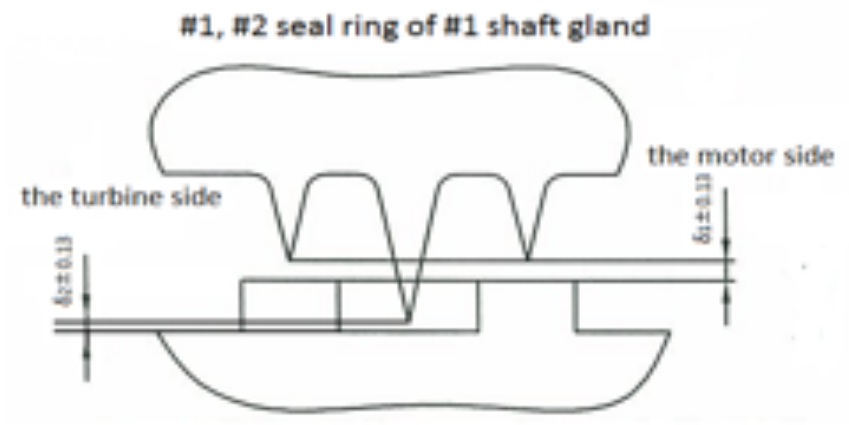

Fig. (14). The diagram of high pressure $\# 1$ shaft gland radial clearance.

For the analysis of the steam flow excited vibration caused by rotor eccentricity, the axis orbit is conducted during the unit vibration as shown in Fig. (15).

When the steam turbine rotates at high speed, it not only rotates around its own center in the bearings but also around another center and does vortex motion. The vortex motion trajectory is the axis orbit. Axis orbit is obtained by using two non-contact sensors that are in the same section of shaft and perpendicular to each other, while collecting data at the same time, a sensor data is termed as abscissa and another as the ordinate.

The normal Orbit should be the ellipse with a little difference between the long axis and short axis having more stability. If the shape and size of the orbit have good repeatability, it indicates that the rotor eddy is stable; otherwise, it is not stable. When the rotor is in self-excited vibration, the axis orbit is often unstable and the size and shape vary with time.

Matlab was used to analyze the collected data for the trajectory. 10 representative sampling points corresponding to the position of rotating shaft in the bearings, high pressure shaft gland and first stage blade tip seal clearance changes were selected as shown in Tables $\mathbf{4}$ and $\mathbf{5}$. (the condition of \#2 bearing is similar to \#1, so the data of \#2 bearing is not listed in this paper).

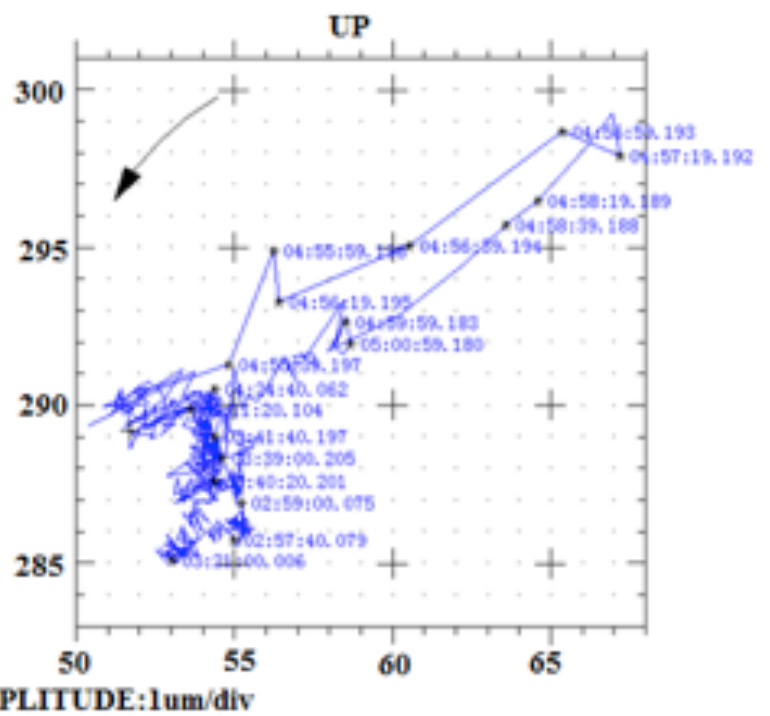

(a) \#1 bearing

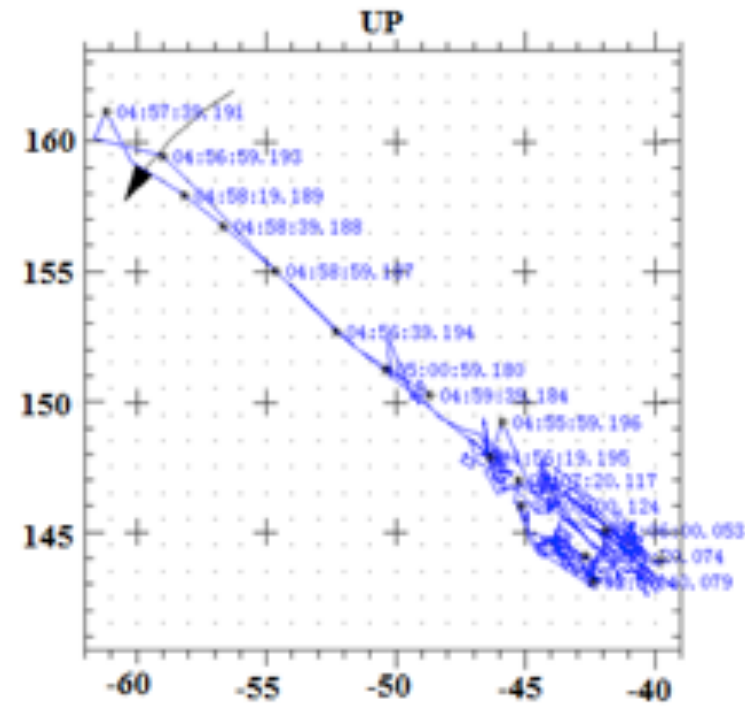

AMPLITUDE:1um/div

(b) \#2 bearing

Fig. (15). The axis orbit graphs.

From the data in Tables $\mathbf{4}$ and $\mathbf{5}$, it can be seen that the shaft sealing gap was negative, so the running process could have been judged if there had been radial rubbing. The seal 
Table 4. The shaft seal clearance corresponding to \#1 bearing axis orbit.

\begin{tabular}{|c|c|c|c|c|c|c|}
\hline & X (um) & $Y(u m)$ & $\delta \max (\mathbf{m m})$ & $\delta \min (\mathbf{m m})$ & $\delta \max (\mathrm{mm})$ & $\delta \min (\mathbf{m m})$ \\
\hline 2 & 55.4 & 287 & 0.5623 & -0.0223 & 0.7123 & 0.1277 \\
\hline 3 & 53 & 285 & 0.5599 & -0.0199 & 0.7099 & 0.1301 \\
\hline 5 & 54.5 & 290.5 & 0.5656 & -0.0256 & 0.7156 & 0.1244 \\
\hline 6 & 56 & 295 & 0.5703 & -0.0303 & 0.7203 & 0.1197 \\
\hline 7 & 65.2 & 298.7 & 0.5757 & -0.0357 & 0.7257 & 0.1143 \\
\hline 8 & 63.5 & 295.6 & 0.5723 & -0.0323 & 0.7223 & 0.1177 \\
\hline
\end{tabular}

Table 5. First stage blade tip seal clearance corresponding to \#1 bearing axis orbit.

\begin{tabular}{|c|c|c|c|c|c|c|}
\hline & \multicolumn{2}{|c|}{ Eccentric (e) } & \multicolumn{2}{|c|}{$\mathbf{R}=610, \delta=0.4$} & \multicolumn{2}{|c|}{$\mathrm{R}=613, \delta \quad 0=0.5$} \\
\hline & $X$ (um) & $Y(u m)$ & $\delta \max (\mathrm{mm})$ & $\delta \min (\mathrm{mm})$ & $\delta \max (\mathbf{m m})$ & $\delta \min (\mathbf{m m})$ \\
\hline 1 & 55 & 285.8 & 0.6410 & 0.0590 & 0.7410 & 0.1590 \\
\hline 2 & 55.4 & 287 & 0.6423 & 0.0577 & 0.7423 & 0.1577 \\
\hline 3 & 53 & 285 & 0.6399 & 0.0601 & 0.7399 & 0.1601 \\
\hline 4 & 54 & 289 & 0.6440 & 0.0560 & 0.7440 & 0.1560 \\
\hline 5 & 54.5 & 290.5 & 0.6456 & 0.0544 & 0.7456 & 0.1544 \\
\hline 6 & 56 & 295 & 0.6503 & 0.0497 & 0.7503 & 0.1497 \\
\hline 7 & 65.2 & 298.7 & 0.6557 & 0.0443 & 0.7557 & 0.1443 \\
\hline 8 & 63.5 & 295.6 & 0.6523 & 0.0477 & 0.7523 & 0.1477 \\
\hline 9 & 58.5 & 292.7 & 0.6485 & 0.0515 & 0.7485 & 0.1515 \\
\hline 10 & 58.8 & 292 & 0.6479 & 0.0521 & 0.7479 & 0.1521 \\
\hline
\end{tabular}

rubbing photo was collected on the scene (Fig. 16) and scratches can be clearly seen in the calculated data.

The formula of Thomas shows that when clearance variation is increased along with the circumferential direction, the steam flow excited vibration force also increases. On the shaft gland and tip clearance variation data analysis, the rotating shaft eccentric is changed through adjusting the shaft position in bearing journals, so as to proceed a step further in reduction of the steam flow excited vibration. At the same time, the axial tip clearance of \#1, 2 bearings are measured. The middle of the bearing clearance is in the scope of this design as both ends of the bearing in the data are too large and exceeded the design value. The measured data is shown in Table 6. Therefore, according to the calculated data by the trajectory and the measured data of bearing axial clearance, appropriate adjustments are made and adjusted data are given in Table 7.

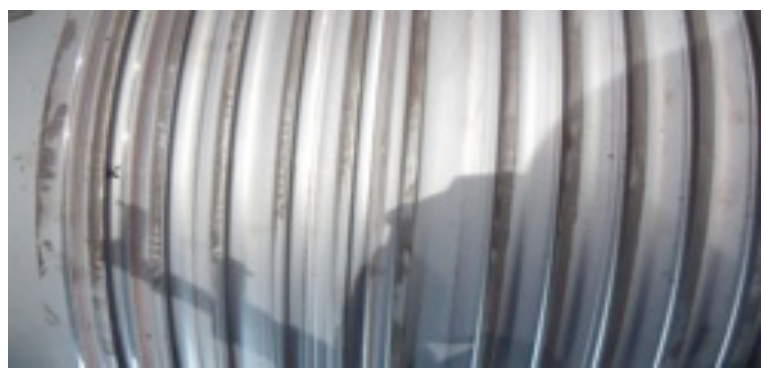

Fig. (16). The shaft seal rub photos.

After bearing clearance adjustment, the axis orbit of units was collected again as shown in Fig. (17).

It can be seen from axis orbit that after adjustment of bearing axial clearance, the axis orbit improved than before; therefore, efforts are underway to load up the test further. Based on the original load limit $960 \mathrm{MW}$, the load gradually increased to $980 \mathrm{MW}$, the maximum value of shaft vibration 
Table 6. Shaft tip clearance data of detection and adjustment (at bearing).

\begin{tabular}{|c|c|c|c|c|c|c|c|}
\hline \multirow{2}{*}{} & \multicolumn{9}{|c|}{ Shaft Tip Clearance } \\
\cline { 2 - 8 } & \multirow{2}{*}{ Design Value } & \multicolumn{3}{|c|}{ Before Adjustment (Measured) } & \multicolumn{3}{c|}{ After Adjustment (Measured) } \\
\cline { 2 - 9 } & & TUR Side & Middle & GEN Side & TUR side & Middle & GEN Side \\
\hline \hline$\# 1$ & $0.47 \sim 0.62$ & 0.62 & 0.54 & 0.58 & 0.46 & 0.45 & 0.45 \\
\hline$\# 2$ & $0.57 \sim 0.72$ & 0.78 & 0.68 & 0.72 & 0.53 & 0.54 & 0.56 \\
\hline
\end{tabular}

appeared in the direction of $2 \mathrm{Y}, 73 \mathrm{um}, \# 1, \# 2$ shaft vibration were within the range of alarm and then loading was continued up to $1026 \mathrm{MW}, 1083 \mathrm{MW}$ while vibration values were normal. The load and the vibration curves are shown in Fig. (18).

\section{CONCLUSION}

Since the startup of the unit's trial, shaft vibration of \#1 and \#2 leads to trip due to exceeding of the limit at high loads. it seriously impacts the unit availability.

In the process of elimination of the vibration of the unit, according to the characteristics of vibration during the

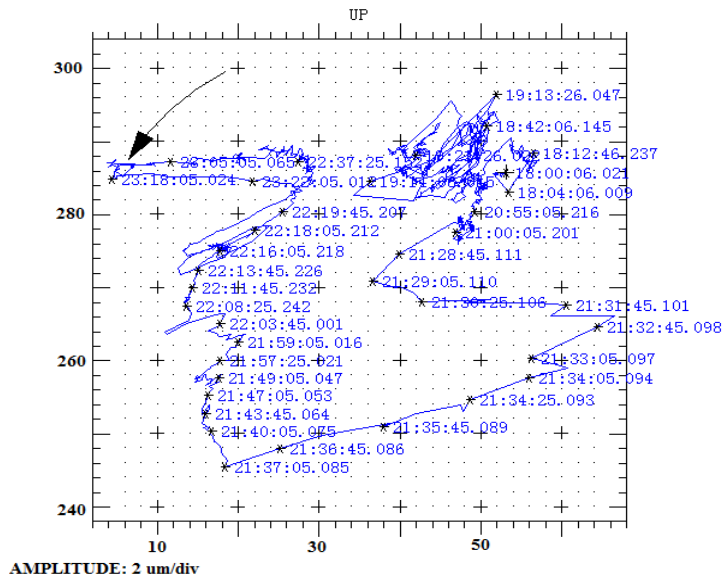

(a) \#1 bearing

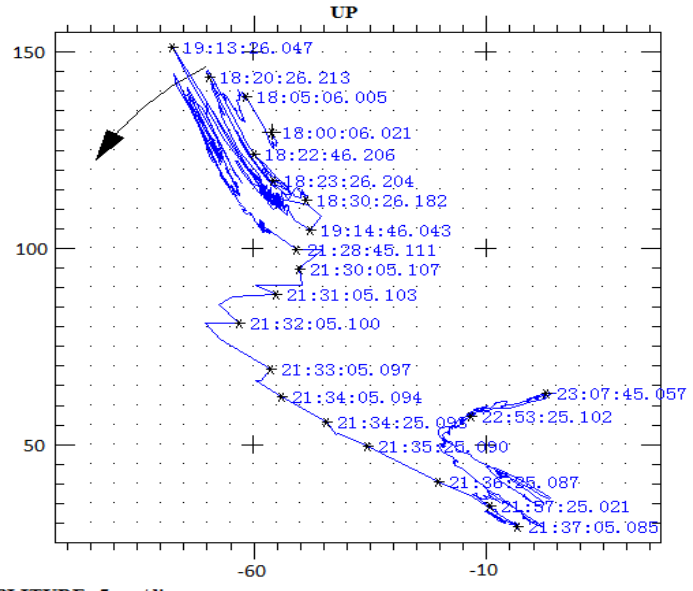

(b) \#2 bearing

Fig. (17). The figure of axis orbit after adjustment. high loads, at high pressure rotor, the vibration was confirmed as the steam flow excited vibration. Based on the causes of the exciting force, improving the static steam force of steam turbine by altering control valve sequence, the steam turbine passed the original tripping load from $928 \mathrm{MW}$ to $960 \mathrm{MW}$, however in the load of $961 \mathrm{MW}$, the turbine vibration crossed the alarm value up to $134 \mathrm{um}$ Although, the rate of vibration was improved, it still existed and the unit could not successfully achieve the rated load. Therefore, the efficacy of eliminating the steam flow excited vibration force by changing the static steam force is limited, so further

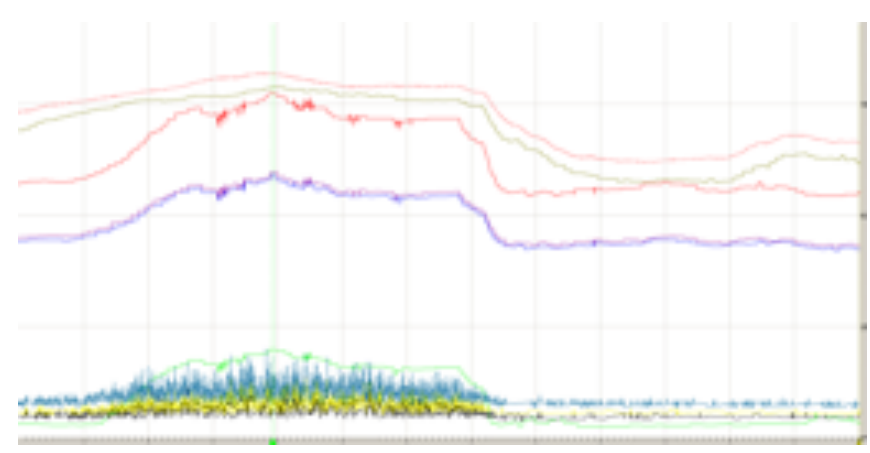

(a) $980 \mathrm{MW}$

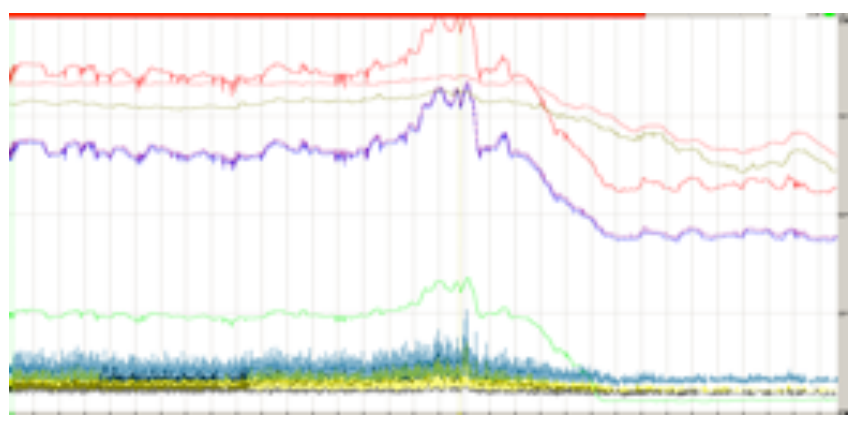

(b) $1026 \mathrm{MW}$

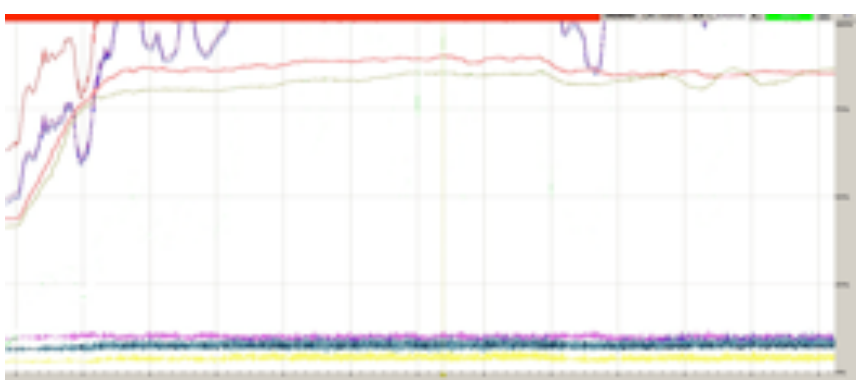

(c) $1083 \mathrm{MW}$

Fig. (18). Vibration curve of different unit load after adjustment. 
analysis is required for the influence of the shaft eccentric on the steam flow excited vibration force. Through the calculation and measurement, the adjusted way of bearing the clearance was found, and anti-rotating tooth was installed at the entrance of the seal, thus raising the unit successfully to the rated load close to the maximum rated power, and the vibration values were within the normal range. The vibration of the load points are shown in Table 7.

Thus, by adjusting valve sequence, the anti-rotating tooth was put into use at the entrance of seal and the shaft tip clearance was adjusted while the turbine steam flow excited vibration problems were solved; the unit successfully achieved the maximum rated load.

Table 7. Before and after the test the vibration on different load point.

\begin{tabular}{|c|c|c|c|c|c|}
\hline & & \multicolumn{4}{|c|}{ The Shaft Vibration } \\
\cline { 3 - 6 } & $\begin{array}{c}\text { Load } \\
\text { (MW) }\end{array}$ & $\begin{array}{c}\mathbf{1 X} \\
\text { (um) }\end{array}$ & $\begin{array}{c}\mathbf{1 Y} \\
\text { (um) }\end{array}$ & $\begin{array}{c}\mathbf{2 X} \\
\text { (um) }\end{array}$ & $\begin{array}{c}\mathbf{2 Y} \\
\text { (um) }\end{array}$ \\
\hline \hline \multirow{2}{*}{ Before the test } & 928 & 248 & 260 & 269 & \\
\hline After valve test & 961 & 86.6 & 134 & 102 & 48 \\
\hline \multirow{2}{*}{$\begin{array}{c}\text { After shaft } \\
\text { tip clearance } \\
\text { adjustment }\end{array}$} & 983 & 51 & 55 & 54 & 73 \\
\cline { 2 - 6 } & 1026 & 22 & 51 & 50 & 64 \\
\cline { 2 - 6 } & 1083 & 31 & 38 & 20 & 37.5 \\
\hline
\end{tabular}

\section{CONFLICT OF INTEREST}

The authors confirm that this article content has no conflict of interest.

\section{REFERENCES}

[1] G. Tang, W. Zhang, S. Lu, F. Mu, and X. Gao, "Steam distribution strategy optimization for 600-MW steam turbine under partial admission conditions," Journal of Electric Power, vol. 48, no. 2, pp. 14-19, 2015.

[2] X. Ding, H. L. Shunl, J. Zhai, and Y. Li, “ Analysis and simulation of stream-exciting force caused by impeller eccentricity in 600 MW steam turbines", Journal of Chinese Society of Power Engineering, vol. 30, no. 5, pp. 342-346, 2010.

[3] X. Zhang, and J. Yang, "Influence of rotor axial shifting on dynamic characteristics in staggered labyrinth gland", Journal of Power Engineering, vol. 29, no. 1, pp. 36-39, 2009.

[4] G. He, L. Zhao, W. Ren, and X. Zhang, "Analyzing and troubleshooting the steam-flow exciting vibration fault for 1000 MW unit", Journal of Electric Power, vol. 47, no. 4, pp. 27-31, 2014.

[5] R. Guo, and J. Yang, "The research of the partial admission influence on seal clearance flow excited force", Journal of Turbine Technology, vol. 52, no. 3, pp. 188-190, 2010.

[6] X. Jiang, W. Li, and H. Peng, "Research progress about the steam excitation force modal of ultra supercritical steam turbine", Journal of Power System Engineering, vol. 24, no. 5, pp. 24-30, 2008.

[7] M. Wang, S. Uu, X. Wang, H. Zhuang, and Y. Dai, "Research on the steam exciting force of governing stage blade of ultra supercritical steam turbine", Journal of Turbine Technology, vol. 56, no. 3, pp. 195-202, 2014

[8] Y. Cui, Z. Liu, C. Shen, and B. Zhao, "On seal-excited vibration Of rotor for utra supercritical steam turbine", Journal of Lubrication Engineering, vol. 36, no. 4, pp. 4-7, 2011.

[9] G. Song, H. Luang, H. X. Zhou, C. Liu, and J. Song, "Cause analysis of sub-synchronous vibration case in turbine-generator units", Journal of Turbine Technology, vol. 56, no. 3, pp. 162-165, 2014.

[10] X. Ding. X. Guo, J. Yang, Y. Lei, and Z. Li, "Influence of labyrinth seal teeth shape on sealed flow field and leakage", Journal of Huazhong University of Science \& Technology (Nature Science Edition), vol. 34, no. 7, pp. 9-10, 2006.

[11] H. J. Thomas, "Unstable oscillations of turbine rotors due to steam leakage in the sealing glands and the buckets", Bulletin Scientifique A J M, vol. 71, pp. 223-236,1956.

\section{ACKNOWLEDGEMENTS}

Declared none. 